\title{
Pedagogic partnership in higher education: encountering emotion in learning and enhancing student wellbeing
}

Jennifer Hill ${ }^{1},{ }^{*}$ Ruth L. Healey ${ }^{2}$, Harry West ${ }^{1} \&$ Chantal Déry $^{3}$

${ }^{1}$ Department of Geography and Environmental Management, University of the West of England, Coldharbour Lane, Bristol BS16 1QY, UK. Email : Jennifer.Hill@uwe.ac.uk and Harry.West@uwe.ac.uk

${ }^{2}$ Department of Geography and International Development, University of Chester, Parkgate Road, Chester, CH1 4BJ, UK. Email : r.healey@chester.ac.uk

${ }^{3}$ Département des sciences de l'éducation, Université du Québec en Outaouais, 5 rue St-Joseph, St-Jérôme, Québec, J7Z 0B7, Canada. Email : chantal.dery@uqo.ca

*Corresponding author: r.healey@chester.ac.uk

\section{ABSTRACT}

Despite emotion being recognised as fundamental to learning, the affective aspects of learning have often been side-lined in higher education. In the context of rising student wellbeing challenges, exploring ways of supporting students and their emotions in learning is increasingly significant. Pedagogic partnerships have the potential to help students to recognise and work with their emotions in their learning in a positive manner. As such, pedagogic partnerships offer opportunities to promote resilience and enhance student wellbeing. In this paper, we develop partnership research in three ways by: 1) considering the ways in which pedagogic partnership may support students to encounter emotions and empower them to develop resilience, leading to positive wellbeing; 2 ) exploring how this process might be achieved in the disciplinary context of geography; and 3) developing an evidence-based model to summarise the potential effect of pedagogic partnership in enhancing student wellbeing. We draw upon two case studies of student-faculty and student-student pedagogic partnership within geography curricula in order to evidence that emotional awareness in learning comes through the joys and struggles of working in partnership. We argue that pedagogic partnership may be developed to support the wellbeing of modern-day higher education communities.

\section{KEYWORDS}

Pedagogic partnership; emotions; wellbeing; academic resilience; geography; borderland space

\section{Introduction}

Developing a 'partnership' approach has become an aspirational goal in higher education around the world, with efforts to shift from faculty-centred to student-centred pedagogies (Bovill et al., 2011). Although there 
are many forms of partnership in higher education (Healey et al., 2014), we are concerned with pedagogic partnership, viewing it as the process of joint working between students and faculty and between groups of students in order to foster engaged student learning and enhance teaching. It is 'a collaborative, reciprocal process through which all participants have the opportunity to contribute equally, although not necessarily in the same ways, to curricular or pedagogical conceptualization, decision-making, implementation, investigation, or analysis' (Cook-Sather et al., 2014: 6-7).

While meaningful partnership working faces some well-documented barriers, including resistance from certain faculty and students, and institutional norms (Bovill et al., 2016; Curran \& Millard, 2016; Murphy et al., 2017), it also has a transformative capacity (Johansson \& Felten, 2014). Engaging students as partners empowers them to co-create their learning, sharing responsibility with one another and with academic staff (Moore-Cherry et al., 2016), and leading ultimately to enhancement for all concerned (Cook-Sather et al., 2014; Healey et al., 2014). Partnership working can engage students more fully with their learning, enhancing their motivation and confidence, developing their meta-cognitive awareness and improving their learning experience and achievement (Healey et al., 2014). Faculty can find themselves reconceptualising learning and teaching as a relational process and consequently feeling reinvigorated with their teaching (Bovill et al., 2011). Such a collaborative approach to pedagogy helps to shift academic conceptualisations of teaching and learning away from ideas of pedagogical solitude (Shulman, 2004) to more of a collective endeavour.

To be successful, partnership working in higher education should be enacted with authenticity, respect, reciprocity, honesty, and shared responsibility for learning and teaching (Cook-Sather et al., 2014). As such, guiding principles for good practice include: working towards a shared vision; fostering inclusive partnerships; nurturing relationships through dialogue and reflection where power is shared equally; accepting partnership as a process with uncertain outcomes; and enacting partnership for transformation (Cook-Sather et al., 2014; Matthews, 2017; Healey et al., 2018). All of these aspects are tied to emotions and thereby move beyond the rational. Emotions shape how deeply and critically people engage with ideas and experiences, and the goals and motivations that inhibit or enable behaviours (Lerner et al., 2015). This means they 'orient people to respond to ongoing events in their environment' and are always 'relational' (Keltner \& Lerner, 2010: 318). In turn, this means that by adopting a partnership approach faculty have the opportunity to foreground the emotions of their students, enabling them to work with their emotions as part of the learning process. 
While a large number of studies have explored the nature, benefits and challenges of pedagogic partnership in higher education (Mercer-Mapstone et al., 2017), emotion and wellbeing are rarely foregrounded (Felten, 2017). And yet, we cannot fully understand the experiences of, or outcomes for individuals in partnership without attending to the emotional context (Hermsen et al., 2017). As such, in this paper we develop a thesis that engaging students in partnership with faculty or peers supports students with the emotions they experience in challenging learning environments. In particular, consciously encountering emotion through pedagogic partnership can move students from negative feelings towards positive emotions, attitudes and learning behaviours, building their resilience and wellbeing. Through this process, negative emotions can be important (and even powerful) precursors to enhancing motivation and learning for some students rather than being viewed as necessarily detrimental. To realise this process, faculty and students must be willing to enter into and work within the borderland spaces of partnership (Hill et al., 2016, 2019) in order to become comfortable with uncertainty and challenge, potentially changing their ideas and behaviours, and becoming more responsible and resilient in their learning. In short, transformative learning (irreversibly changing knowledge, emotions, attitudes and behaviour) is prompted through the struggles that are exposed and shared through dialogue in partnership. We will highlight that faculty should not divorce the affective realm of learning from the cognitive as wellbeing issues rise into sharp focus for higher education students across the globe. Indeed, it is by consciously uniting these two realms that learning can be tackled holistically, supporting students to develop positive emotions and resilient academic behaviours through meaningful partnership interactions.

Within this context, the aims of our paper are to develop partnership research in three ways, dealing respectively with the 'what', 'where' and 'how'. We contribute to the existing literature by:

1) considering the ways in which pedagogic partnership may support students to encounter emotions and empower them to develop resilience, leading to positive wellbeing;

2) exploring how this process might be achieved in the disciplinary context of geography; and

3) developing an evidence-based model to summarise the potential effect of pedagogic partnership in enhancing student wellbeing.

Our paper is thereby situated at the intersection of three broad areas: pedagogic partnership; student emotions and wellbeing; and the characteristics of geography as a discipline (Figure 1). 
Figure 1. The research remit: the intersection between pedagogic partnership, student emotions and wellbeing, and the discipline of geography

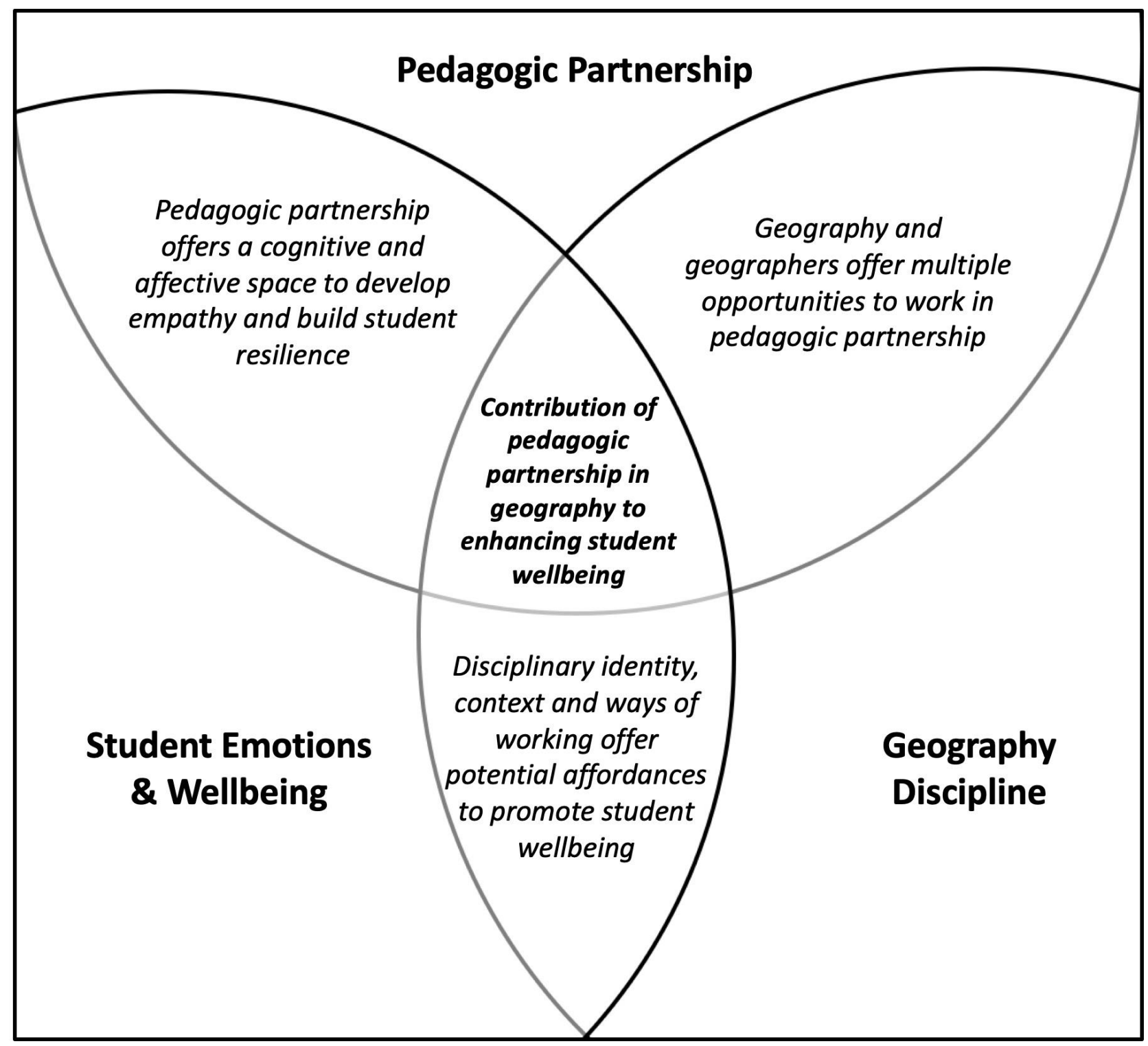

To address our aims we first introduce the concepts of emotion, resilient academic behaviours and wellbeing. We progress to outline two case studies of student-faculty and student-student partnerships within geography curricula, which expose student emotions and illustrate a shift in learning behaviours, resilience and wellbeing. We then use evidence from our case studies and selected wider literature to explore how this process might be achieved in the disciplinary context of geography. We conclude by presenting our evidence-based model, which summarises the potential effect of pedagogic partnership in enhancing student wellbeing. We 
acknowledge that not all faculty members will feel comfortable or personally equipped to foreground the emotions that attend learning. As such, we offer advice and practical suggestions to reduce faculty anxiety.

\section{Conceptual context: emotions, resilient academic behaviours and wellbeing}

In the last 15 years we have seen growing interest in educational research on emotions and wellbeing at all stages of education (Efklides \& Volet, 2005; Schutz \& Pekrun, 2007; Pekrun \& Linnenbrink-Garcia, 2014). This concern partly relates to a shift in the student population in universities across the globe, whereby the student body has significantly diversified and expanded (Jacklin \& Robinson, 2007) while experiencing ongoing challenges of living independently, autonomous learning and peer competition (Anthoney et al., 2017). Alongside this, students face significant pressures including competition for graduate jobs and financial challenges established by high tuition and living fees (Anthoney et al., 2017). These factors have meant that student mental health problems in higher education continue to rise internationally (Ferguson, 2017). In one study, based on a sample of 2000 teenagers in the UK, 17\% had considered suicide (Hertz, 2016; cited in Kneale, 2018); with demand for wellbeing and mental health services in UK universities rising by $50 \%$ between 2011 and 2016 (Anthoney et al., 2017). A similar issue has been found internationally, with an estimated 20\% of Australian students experiencing a mental health issue (Carter et al. 2017), and a fifth of Canadian postsecondary students identifying as depressed, anxious or battling other mental health issues (Pang, 2017).

In order to enhance student wellbeing in higher education, we need to start working more closely with the emotional elements of their learning experience. Beyond the cognitive domain, in which students process information and construct meaning (Bloom et al., 1956), the affective domain engages students' with their emotions, feelings and values in response to a learning task (Krathwohl et al., 1964). The affective domain influences an individual's perception of an activity and therefore their approach to any particular learning experience. Affective outcomes 'foster deep approaches to learning, leading to better student performance due to higher levels of understanding' (Boyle et al., 2007: 301-302). Emotion can therefore be understood as 'an essential part of the thinking process', rather than 'an obstacle to or a distraction from rational thought' (Felten et al., 2006: 41). In short, emotion is fundamental to learning (Felten et al. 2006) and hence intrinsically linked to student wellbeing (Deonna \& Teroni, 2013).

We view student wellbeing as an umbrella term that emanates from the achievement of a number of personal attitudes and behaviours (Table 1). Positive emotions, and self-regulative and self-efficacious behaviours, lead to academic resilience and positive wellbeing. Psychological research demonstrates that 'positive emotions 
broaden the scopes of attention and cognition, and, by consequence, initiate upward spirals toward increasing emotional well-being' (Fredrickson \& Joiner, 2002: 172). This is because positive emotions enhance an individual's belief in their own abilities (self-efficacy) and students with high self-efficacy for learning use more critical thinking to find ways of achieving an end result (Ritchie, 2016) and persist with, and are resilient in, their learning (Zimmerman, 2000). People and structures within higher education can create factors that lead to stress and anxiety amongst students (Jacklin \& Robinson, 2007). Therefore, it is important to recognise, that academics can influence the self-efficacy beliefs and resilience of their students, guiding them through the learning processes they need to achieve for themselves and helping them to 'bounce back' and cope with academic stress. In this way faculty can work on ways of reducing stress to enhance wellbeing by developing positive outlooks for students and supporting the growth of resilient and confident learners (Anthoney et al., 2017). We argue that this process may be enhanced through pedagogic partnership working.

Table 1. Glossary of key terms.

\begin{tabular}{|l|l|}
\hline Emotions & $\begin{array}{l}\text { Emotions are relatively brief and context-specific responses to experiences, } \\
\text { objects, or causes (Felten, 2017). They 'structure relations ... [and] guide social } \\
\text { interactions', organizing 'the interactions of individuals in meaningful } \\
\text { relationships' (Keltner \& Haidt, 1999: 506, 510). }\end{array}$ \\
\hline Resilience & $\begin{array}{l}\text { The ability to 'adjust to adversity, maintain equilibrium, retain some sense of } \\
\text { control over their environment, and continue to move on in a positive manner' } \\
\text { (Jackson et al., 2007: 3; cited in Anthoney et al., 2017: 405). }\end{array}$ \\
\hline Self-efficacy & $\begin{array}{l}\text { 'A person's perception that he or she has the skill and capability to undertake a } \\
\text { particular action or task' (Bartimote-Aufflick et al., 2016: 1918-1919). }\end{array}$ \\
\hline Self-regulation & $\begin{array}{l}\text { The ability to control one's behaviour, emotions, or thoughts, appropriate to the } \\
\text { given context or situation (Cook \& Cook, 2014). }\end{array}$ \\
\hline Wellbeing & $\begin{array}{l}\text { 'A sustainable positive mood and attitude, health, resilience, and satisfaction with } \\
\text { self, relationships and experiences' in their educational environment' (DEECD, } \\
\text { 2010: 1). }\end{array}$ \\
\hline
\end{tabular}

When students are aware of their learning environment, and the ways they can approach and shape their learning experiences, they are in a strong position to become self-regulated learners. Self-regulation is essentially the self-directive process by which learners can transform their mental abilities into academic skills (Zimmerman, 2002). Self-regulation and self-efficacy have a close relationship, informing and affecting one another throughout learning (Ritchie, 2016). As with self-efficacy, skills of self-regulation can be developed through activities such as self-evaluation, organising and transforming material, goal setting and planning, seeking information and creating self-consequences (Zimmerman \& Martinez-Pons, 1990). As such, selfregulated and self-efficacious students tend to be high achievers (Gutman \& Vorhaus, 2012). 


\section{Case studies: encountering emotion through pedagogic partnership in geography}

Geographers have been both vocal advocates for, and early adopters of, pedagogic partnership (Hill et al., 2016; Moore-Cherry et al., 2016). This may be partly attributable to the breadth of the subject and the diversity of learning spaces that geographers inhabit. Our case studies set out to explore how pedagogic partnership in the disciplinary context of geography may offer fertile ground to consciously encounter emotions and empower students to develop resilience, leading to positive wellbeing. Through these case studies we also examine whether our disciplinary identities, contexts and ways of working provide particular affordances to us foregrounding emotion through partnership working. It should be noted that we take a broad view of pedagogic partnership between faculty-students and student-student in this paper. We refer to partnership working when students and faculty, or groups of students, work collaboratively to enhance learning, enabling both faculty members and students to see the learning environment through another frame. Pedagogic partnership embraces an authentic dialogic approach to learning and teaching, recasting how students and faculty view their roles and responsibilities within their education, prompting them to assume the identity of co-learners.

\section{Case study data collection}

The authors present two case studies, based on research projects they were aware had taken students into challenging partnership learning spaces in the formal curriculum, directly encountering emotions and evidencing altered learning behaviours and attitudes. The principal investigators of these projects (four faculty members) were provided with the research aims delineated above and invited to answer a series of questions that prompted them to consider, in relation to their partnerships: how the student-faculty or student-student relationships drew forth positive and/or negative emotions in their students; whether these evolved over time as the partnership progressed; whether these emotions intersected with student learning, behaviour and performance over the short or long term; whether they believed that foregrounding emotions through partnership had promoted wellbeing in their students; and whether there was anything about being a geographer that helped them to work in partnership and to encounter emotion for positive benefit. The respondents were requested to answer the questions using relevant primary data collected during the lifespan of their projects and with reference to the emotions they observed during their projects. Original data collection methods, which passed through the home institutions' ethical review processes, can be found by reviewing Hill \& West (2019) (for case study 1), and Marvell \& Simm (2018) (for case study 2). All respondents provided written answers to the interview questions, comprised of direct student testimony (drawn from 150 
students) and their personal observations and reflections. These written accounts were examined by two of the authors (Hill and West) to draw out key themes. They identified themes separately at first and then together to review and negotiate their interpretations. This convenience sample allowed access to data consciously collected to access student emotions. However, it should be noted that whether collected from primary sources (direct student testimony) or secondary sources (indirect staff observation), we present subjective interpretations of complex affective feelings, which students and staff might not be able to make sense of or articulate with complete clarity. Equally, some students might choose to self-censor responses about their emotions when asked to reflect upon them by a tutor for various reasons, including if they believe this implies academic weakness.

\section{Case study 1: Student-faculty assessment feedback dialogue}

This case study explores changing student emotions and learning behaviours linked to an assessment intervention implemented in a second year undergraduate geography course at a large teaching-oriented British university (Hill and West, 2019). Running over 12 weeks, the course aims to provide students with the opportunity to study ecological principles and to begin to appreciate how these may be applied to problems in conservation biology.

The students choose an essay title from a selection included in the course guide. They write a considered draft of their chosen essay, which is then discussed in an individual face-to-face meeting with the tutor. These 'feedforward' meetings are open and friendly, encouraging collaborative co-learning and candid exchange of ideas through dialogue. They begin with the tutor purposefully asking each student if they are 'ready for feedback', clarifying that the meeting will focus on the performance gap (i.e. areas that are currently weak and need further development). The tutor and student together discuss how to discern key aspects of the essay question, and how to apply appropriate knowledge and skills to develop an effective answer, building on the strengths of the draft.

In terms of summative assessment, students write a self-reflection of their essay progress and self-assess their draft ( $25 \%$ of the course mark). A week later they submit their revised essays ( $75 \%$ of the course mark). After final grading, the students are invited for a further individual feed-forward meeting, where their final marked essay is discussed in relation to future assessments. Dividing the assignment into these distinct phases generates an iterative feedback cycle which facilitates engagement with feedback and the prospect of improvement from one task to the next, building student agency and self-efficacy. 
Although the intent of the faculty member in implementing this assessment approach was primarily to improve student performance, it uncovered the inherently emotional experience for students of receiving assessment feedback. In the face-to-face meetings, even though a good deal of time was spent discussing cognitive aspects of assignments such as their structure and content, the receipt and processing of this feedback by the students was charged with emotion as they absorbed the formative indicative grade and what the comments meant for their learning and potential success. In effect, their thinking could not be divorced from their emotions as they firstly received their draft grade and feedback, and then strived to adjust their actions and self-concept. As such, the meetings purposefully acknowledged the students' emotions and deliberately brought them into discussion through a conscious and directed process. As their instructor, Hill believed that her geography disciplinary identity helped her to empathise with the diversity of students on her course because she felt accustomed to dealing with multiple perspectives and complex problematics. Additionally, she commented that working with human geographers and wider disciplinary practitioners during her career afforded her a sense that 'co-learning with students' 'felt relatively natural'. She saw it as 'another working partnership where trust, mutual respect and honest conversations are key to progress'. Equally, the applied nature of the essay questions, concerning a complex physical environment, meant that there was much to debate within answers and the students seemed keen to discuss how they might best communicate progressive arguments in their emerging essays, seemingly accepting of the problem-solving nature of geographic pedagogy.

When asked how they felt about receiving feedback at the start of their individual meetings some students commented about feeling nervous and uncertain, and then worried, anxious or even 'ashamed' if their perception of their performance at that point fell short of their desired level:

'I was worried when I handed in my draft, because I knew it wasn't brilliant'

'It is quite disheartening when you're like I tried so hard on this and there is still so much more I can do'

Recognising students' emotional vulnerability and sense of insecurity, the meeting was designed to interweave constructive academic commentary with discussion about what the student might do after the meeting to attend to the comments and how this might make them feel and act differently as a learner. Through reciprocal dialogue, the faculty-student team worked together with a common sense of purpose to ensure the students were: aware of what the feedback meant; cognisant of strategies by which the feedback could be 
acted upon; and empowered to implement these strategies immediately after the meeting (Winstone et al., 2017). The key was to persuade the students they had capabilities that could be developed over time rather than fixed abilities that might limit their achievements. The disheartened student above, for example, followed that sentence directly by saying:

'But it does make you work harder at the end of the day, because you know what to improve on and how'

In the face-to-face meetings the students effectively learnt 'head-on'. This was an affective encounter in which their work was being judged, often below their desired level, and this required emotional capacity to receive, process and build upon (Forsythe \& Johnson, 2017). For some students, this was a challenge. They commented how they felt 'knocked back', 'dented' and 'annoyed' at themselves upon receiving the draft grade and feedback. However, the students generally coped well in this unsettling and disruptive situation, eventually recognising the need to understand their weaknesses in order to improve their work. Students commented on how they tried to remain positive and develop a sense of optimism regarding the meeting and feedback, whether they thought their essay was good or still required significant improvement. They therefore viewed the meeting as an opportunity to receive constructive formative comment on their work as it progressed:

'I was fine receiving the feedback because without it I wouldn't have improved ... I think to get better you have to get criticised in a constructive way'

'It [the meeting] was more helpful than anything. I didn't think it [the draft] was perfect, so I'm not expecting to come in here and be told that'

Following the face-to-face meeting students highlighted an improved ability to 'decode' feedback through questioning and consequent tutor explanation, allowing them to understand better the tutor's intentions (Orsmond et al., 2013). Clearly, entering into dialogue during the meeting had compelled the students to engage critically with their work. As a result, they gained greater understanding of the written tutor feedback through verbal clarification and use of exemplars:

'When I've had drafts handed back to me written over, I don't understand what they're trying to say. I can ask you questions if we're talking to each other about it, it's easier to see things'

Gaining feed-forward before final grading allowed the students to discover if they were tackling the essay appropriately, deterring bad practice. The dialogic meetings increased student confidence and motivation to act upon the feedback as they prepared their final submissions because they had a clearer idea of task 
expectations and a more secure sense of learning (Carless et al., 2011). Students commented on having a clearer 'sense of direction' and an opportunity to improve their work to achieve a higher grade:

'It made me feel good because I was hopeful. I knew I had things to do that would get me a better mark, so I felt quite motivated'

'It does make you work harder at the end of the day, because you know what to improve on ... and how to do $i t^{\prime}$

Consciously encountering and talking through emotions in a collaborative manner supports a personalised and inclusive learning experience; a key aspect of effective partnership working (Moore-Cherry et al., 2016). The students commented positively about this, noting it to be far more meaningful than generic cohort feedback in helping them to improve their work, and they also noted that the individualised nature of the meeting made them feel cared about:

'Generic comments can be good ... but you never know whether they are applicable to you or not. So getting personalised feedback is really useful'

'I definitely felt like you cared about what [grade] I was getting'

Students reported that they altered their behaviour after the meeting, both within-task and with respect to post-assignment self-regulation. As a result, students commented on how they viewed assessment and feedback differently and would progress to their next assignment with a revised set of emotions and attitudes. They self-avowed to increased self-efficacy, believing more strongly in their capabilities to accomplish assignments in future, and they expressed a desire to continuously improve throughout the remainder of their studies:

'I definitely feel more confident ... being able to prepare, structure and write in the future. Not only will I now be able to repeat these steps ... but I will also be able to self-critique and identify mistakes or weak areas that I may not necessarily have done before'

'I really want to take the feedback I got from doing this module to improve my [essay writing] style. There is no point in me going through education without trying to improve'

The explicit attention paid to the interplay between emotion and intellect throughout this feedback process has enhanced student achievement within the course. The performance of the students improved significantly 
after the assessment intervention. The mean course mark from 2011-2013 (pre-intervention) ( $n=69$ students) compared with $2015-2017$ (post-intervention) ( $n=72$ students) increased by $7 \%$ from $56 \%$ to $63 \%$. Students wrote less descriptively and built stronger arguments, offering more critical depth based on evidence from literature. Additionally, in the final year, students who took the course performed, on average, $4 \%$ better than those who did not. Falling just short of a statistically significant increase, the results nevertheless highlight that the self-avowed changes in student learning behaviour are having some form of positive impact on their achievement. The case study bears witness to the students developing knowledge, confidence and identity as successful learners, impacting on engagement and success over the longer learning journey.

Through these dialogic feed-forward meetings, which drew on many aspects of pedagogic partnership practice, students' cognitive and affective processes were verbally articulated, externalising their learning and making it tangible. Negative emotions for some students, such as anxiety and worry, were transformed into positive emotions such as enthusiasm and pleasure. The relational interactions and collaborative reflections in the meeting also had longer-term effects on student self-regulatory and self-efficacious behaviours, relating not only to the specific assessment task but beyond to other second year assignments and into their third year of study. By creating a safe and nurturing learning environment and a framework of positive experiences, positive beliefs were built and/or strengthened, enabling the students to approach new tasks with confidence and security and to perform well. Instead of neglecting emotions, this case study demonstrates that we can use partnership to positively harness their central role in the teaching and learning process.

\section{Case study 2: Student-led peer teaching during international fieldwork}

Our second case study explores whether bringing emotion into focus in learning might be facilitated by the signature pedagogy of the discipline - fieldwork. Bounded learning spaces, in the form of classrooms and lecture theatres, are integrally linked to specific, and often transmissive, teaching and learning approaches. By contrast, the fluid, unpredictable and boundless nature of fieldwork spaces support relational partnership working (Fuller at al., 2006; Boyle et al., 2007), which supports a collaborative and adaptive ethos, possibly rendering it less radical to negotiate emotion in these contexts (Cook, 2008; Wright \& Hodge, 2012). As such, fieldwork spaces can be used as borderland spaces (Hill et al., 2016), destabilizing traditional power hierarchies and identities as students work in partnership with each other and with faculty members.

Alan Marvell and David Simm have written extensively about student-led peer teaching and learning on international fieldtrips (Marvell, 2008; Marvell et al., 2013; Simm \& Marvell, 2015; Marvell \& Simm, 2018). 
International Fieldwork (now Advanced Geographical Fieldwork) is a final year undergraduate course run at a teaching-intensive university in the UK, characterized by the co-production of the fieldtrip by student groups with faculty. A student-led field teaching and learning strategy is adopted whereby students direct the learning of their peers by planning the logistics, and organizing and delivering presentations in the field for part of the field course. Thus, the students have significant scope for negotiating the content and nature of their field activity, effectively authoring their field course and rendering it more meaningful to them. By adopting this partnership approach, the students are able to build an ethos of shared learning experiences and with it an increased sense of autonomy. The course is delivered through a series of lectures and workshops, culminating in a five-day fieldtrip to Barcelona, Spain. Students work in groups of about four to five, researching a topic in advance of the fieldtrip to deliver as an extended presentation with a learning activity in the field. Faculty act as facilitators, offering advice and guidance, monitoring progress and, where necessary, intervening to resolve issues. Each group submits a fieldwork proposal outlining their project, proposed itinerary and activity, and faculty provide formative feedback to enable students to refine their ideas and clarify their thoughts.

Responding to our questions, Marvell and Simm comment that students were often in a heightened emotional state during the fieldtrip noting that recurrent words used by students were 'challenging' and 'stressful'. The students were often anxious, and expressed uncertainty and concern about preparing and delivering their in situ activities:

'We were all quite nervous about it, because obviously, it is quite daunting the fact that we had such a long presentation, we have all of the factors we don't know what's going to happen when we are out there'

But for most students, this initial apprehension changed to positive feelings once their presentation was finished:

'I loved it ... felt it was successful ... every question we asked we got an answer, the interaction was really, really good'

'... left every single one of us with feelings of excitement and enthusiasm'

The confidence of the students increased and they began to identify as successful participants in the field course, both in terms of their own learning and that of their peers. Marvell and Simm note that the students became more aware of the positionality of academic power: 
'Probably for the first time students start to realise that they are generating knowledge and understanding that is new to their tutors - this can become a liberating feeling of self-affirmation of their own ability and skills. Basically the students mature academically and personally'

The two faculty members identify that the emotional responses of their students changed over time, seemingly becoming less intense. They interpret this as: students reflecting with less emotion after time has passed since their presentations compared with verbalising their experiences when they were fresh; students filtering out emotion in written work, possibly linked to perceptions that feelings should be stifled in academic writing; or students reaching a deeper transformative state in their understanding of these emotions.

Empowered through their in situ peer-teaching to discover knowledge, make connections within a spatial context and deliver a learning experience to others, the students engaged at a deep level with their learning, each other and the places they visited. They showed great respect and attentiveness to their peers due to sharing a mutual experience:

'When participating in ... [another group's] activities I found that I was able to empathize with them from being in their position myself'

'Within our presentation ... we attempted to keep the students looking around and always questioning the environment they were in'

Marvell and Simm highlight a growing awareness in the students of their own abilities and that of their peers. The students began to reflect upon and critique good and bad practice, and often sought to adapt their own delivery, which was further reinforced by formal peer assessment. They remarked about being challenged beyond their 'comfort zone', but ultimately found the peer presentation experience to be rewarding and often liberating:

'For the first time I found myself becoming less of a passive student who just writes notes. I was suddenly asking questions and contributing to discussions; something which I usually find daunting'

The faculty members call this process 'gentle critique', with students learning from one another rather than from tutor feedback, the latter of which the students can perceive as more starkly highlighting knowledge and skill deficits. Marvell and Simm postulate that this process is more prone to develop resilient behaviours in students as they make mistakes together, sharing the burdens as well as the successes of learning. 
Some students experienced transformative learning as they changed their frame of reference and level of understanding. It was clear that such students had experienced a learning journey:

'Looking back ... before the fieldtrip, I can see how closed-minded I was. I had not anticipated how enlightening the fieldtrip would be, or how much my knowledge and skill range would expand'

The immersion of students in their learning in the field influenced their affective domain leading to deeper learning. They demonstrated heightened self-awareness of relational experiences, which transformed their thinking and skills of self-regulation:

'Every day I was subject to new ways of thinking, feeling and studying about topics ... I realised lived experiences are more powerful in promoting learning in comparison with desk-based research ... With this deep learning approach, I am able to apply wider theories to my observations, even after the fieldtrip'

This represents not only an enhanced meta-cognitive awareness of the situated nature and construction of knowledge but heightened emotional sensibilities.

The shift in power relations that accompanies peer-to-peer teaching can throw up the challenge of trust, particularly where students view academics as the only authorities. Some students were anxious about the academic standards and content of some of the field presentations:

'I felt that they had less authority and I ... found myself not as unreservedly willing to believe everything that was being said'

Placing students outside their academic comfort zone, in spaces that alter their identities and arouse their emotions, must be carefully managed and monitored. Goals must be appropriate to the academic level and background of the students (not setting up students to fail), and scaffolding must be sensitive and appropriate.

Marvell and Simm finish by noting that the majority of students find peer-to-peer teaching and learning demanding but rewarding. They also highlight that student performance is generally better for this course compared with other courses taken by the cohort. They call the pedagogic partnership experienced on the fieldtrip an 'academic and emotional liberator', noting that it leaves a sustainable mark on individual and group learning behaviours. This highlights that faculty can guide students from negative feelings of doubt and uncertainty towards positive emotions, attitudes and learning behaviours in challenging learning environments, building their resilience and wellbeing. 
To summarise, this case study demonstrates that the social fieldwork context, supporting meaningful peer-topeer collaboration in learning, disrupts the passive inertia of the bounded classroom. The field context allows alternative expressions of identity, including emotional responses, as experienced in borderland spaces of learning partnership (Hill et al., 2016, 2019). Students' emotions are initially quite negative as they are pushed beyond their comfort zone. But they progress to more positive emotional responses, and demonstrate skills of self-management and self-efficacy. These are feelings and attitudes that 'enhance learning' and lead to a more powerful 'attachment' to a particular learning context (Graetz, 2006: 62). There seems to be a reciprocal relationship between affective and cognitive learning, with each simultaneously mediating the other (Golubchikov, 2015), and this can be consciously directed to support student resilience and wellbeing.

\section{Partnership, encountering emotion and the discipline of geography}

Our case studies evidence emotion as an integral component of pedagogic partnerships. Along with wider literature, they also demonstrate that partnership working and dealing with the affective domain might be well supported in geography through the nature of our disciplinary identities and ways of working. There are many characteristics of geographers (Hill et al., 2018) that might equip them to engage in partnership working. These characteristics are by no means confined to geographers, rather we tentatively suggest that the subject area requires the development of particular ways of thinking and working that also underlie effective partnership practice. Geography faculty, for example, are accustomed to researching and teaching about uncertain, dynamic and unpredictable problems and sometimes even wellbeing issues directly (see Schwanen \& Atkinson, 2015). As such, geographers may be comfortable with such issues as they arise in partnership working. Students studying these issues may empathise deeply with the people and environments in these real-world challenges, drawing forth emotional responses. In this way, disciplinary content sensitises faculty and students to the affective domain, possibly facilitating the broader acknowledgement of emotions in learning.

The subject of geography involves the consideration and evaluation of a range of complex, and possibly conflicting, perspectives which help geographers to become sensitive to the situated nature of knowledge production (Rose, 1997). This helps geography faculty to see students as diverse and emergent learners and hence they appreciate the need to treat their students personally, as individuals. This situated understanding also supports geographers to embrace relational thinking and consider the constructions of 'self' and 'other', for example. Geography faculty may therefore recognise that students have multiple and intersecting 
identities (Felten et al., 2013), providing an opportunity for both faculty and students to reconceptualise their roles and challenge traditional power hierarchies to form inclusive and effective pedagogic partnerships.

Added to this, the signature pedagogy of fieldwork (Shulman, 2005) offers an accommodating environment that enables different ways of knowing and doing, and allows alterations to faculty and student identities. This leads it to be common practice that geography faculty work and learn with their students (Marvell et al., 2013; Moore-Cherry et al., 2016). Viewing themselves as learners, geography faculty may be mindful of their own processes of meta-cognition and wish to assist their students to understand these processes.

Whilst the above are aspects of a geographer's identity that may facilitate partnership working and encountering emotion, geography faculty cannot lay sole claim to these affordances. Equally, there are other characteristics of both faculty and students that need to be considered in shaping the emotional encounters of pedagogic partnerships in geography. These include individual learner approaches and teacher personalities, and how these might or might not enable participation in such partnerships. Additionally, our case studies highlight a role for geography faculty that moves beyond understanding of disciplinary content to embrace a broader range of academic and emotional literacies. This begs the question of whether we are prepared, or have time, to teach such broader literacies to our students, combined with our disciplinary knowledge and ways of doing. Further research into disciplinary identity, personality types and learning approaches, which may make certain individuals more inclined towards partnership practice, may illuminate the relative importance of these attributes.

\section{Conclusion: an evidence-based model of pedagogic partnership and student wellbeing}

In this paper we have developed a thesis that pedagogic partnership in higher education offers fertile ground to purposefully encounter emotions and empower students to develop positive feelings, attitudes and learning behaviours, making them more resilient. We now present this thesis graphically, as an evidencedbased model of the potential effect of pedagogic partnership in enhancing student wellbeing (Figure 2). 
Figure 2. The potential effect of pedagogic partnership in enhancing student wellbeing.

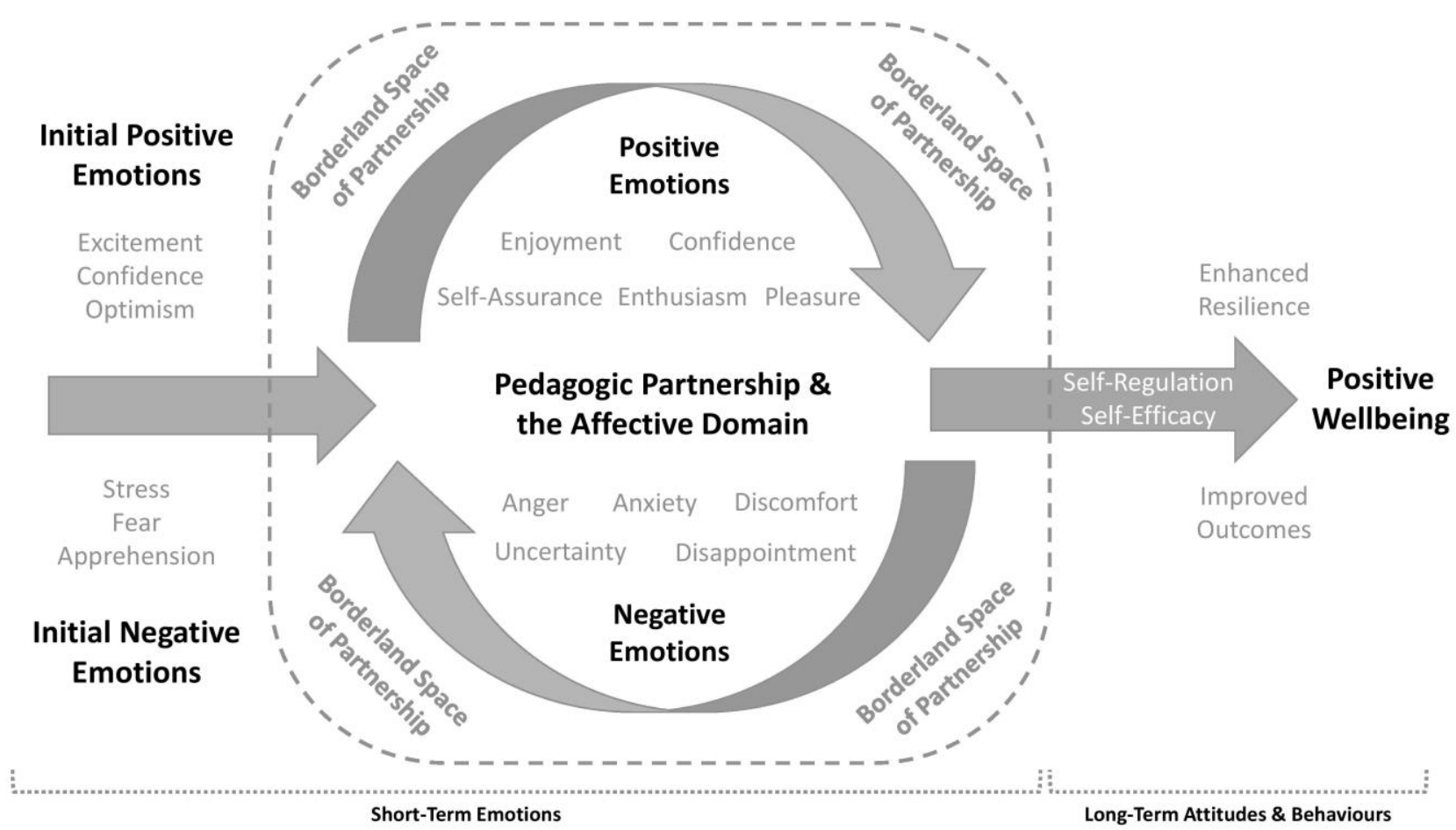

Paradoxically, in the novel and challenging borderland contexts of pedagogic partnership, students need support to cope with a range of emotions that are brought to the fore. And yet the very characteristics of effective partnership working also help to establish a safe and caring space where students can trust that their feelings will be respected, worked with, and possibly re-directed for the better. Through open dialogue with students, academic staff can expose their own struggles with learning and normalise the emotions that underlie the development of knowledge. They too encounter their emotions in the borderland space of pedagogic partnership, which can lead to long-term changes in their attitudes and behaviours (an area of research that warrants further attention).

Our case studies evidence that transformation comes through the cognitive and emotional joys and struggles of learning in borderland spaces of partnership. Pedagogic partnership, although challenging at first and perhaps drawing forth negative emotions, supports engagement with the academic process and is ultimately empowering. Over the longer term, partnership enhances in students the academically resilient behaviours of self-efficacy and self-regulation, boosting learning outcomes and maintaining wellbeing. In essence, Figure 2 demonstrates a conscious displacement of learning, allowing partnership in geography to work students through the precarious nature of learning in a controlled and supported environment, scaffolding them 
towards security and positive wellbeing through the acquisition of resilient academic behaviours. Furthermore, our examples heed the calls of many practitioners to make partnership working more inclusive (Felten et al., 2013; Moore-Cherry et al., 2016; Bovill, 2017).

In calling for openly attending to emotions in pedagogic partnership we are not advocating for faculty to become counsellors. Equally, we are not trying to tell students what or how to feel. We are calling for an opening up to the possibilities and exploring the potential that partnership working can offer to enhance wellbeing. We recognise that this may not be easy for faculty. They may legitimately fear that they will not be able to adequately or safely address student emotions. Offering practical advice to support staff, we suggest relating to students in ways that are welcoming, hospitable and attuned to them as individuals. This can be achieved by adopting active student-centred and social pedagogic approaches such as fieldwork, group work, inquiry-based learning and authentic assessment. Institutional Educational Developers may offer training in these types of practices and support academic staff to work positively with the emotional aspects of learning. They may also know of other colleagues across the institution who are practicing affective partnership pedagogies. Furthermore, faculty members might learn from one another through co-teaching with colleagues, gaining support and learning from them, or simply sharing the emotional labour of teaching. We recognise that this type of practice may not be for everyone, but by ignoring the emotions that are intrinsic within and shape learning, we threaten to limit our students' learning experiences and achievements. Working in partnership to collaboratively develop our students' positive feelings, learning behaviours and wellbeing, we can maximise the potential for sustainable learning and academic success. With further support, pedagogic partnership may be developed beyond the more direct cognitive benefits, addressing some of the key wellbeing needs of modern-day higher education communities.

\section{Acknowledgements}

We thank Alan Marvell and David Simm for answering our research questions and for revisiting their partnership work in the light of student emotions and wellbeing. Equally, we thank all the students who participated in these projects. Quite simply, it is their time, given so generously, that will improve the higher education experience for successive cohorts. We thank the Organising Committee of the INLT Collaborative Writing Retreat and all the participants present in Quebec for their comments on our work as it developed. Finally, we are grateful to the anonymous reviewers for their helpful comments on our manuscript, which have helped to refine the clarity of our argument. 


\section{References}

Anthoney, J., Stead, R. \& Turney, K. (2017). Making connections and building resilience: developing workshops with undergraduates. Knowledge Management \& E-Learning, 9, 404-418.

Bartimote-Aufflick, K., Bridgemanb, A., Walker, R., Sharmad, M. \& Smith, L. (2016). The study, evaluation, and improvement of university student self-efficacy. Studies in Higher Education, 41, 1918-1942.

Bloom, B. S., Engelhart, M. D., Furst, E. J., Hill, W. H. \& Krathwohl, D. R. (1956). Taxonomy of Educational Objectives. The Classification of Educational Goals, Handbook I: Cognitive Domain. New York, NY: David McKay.

Bovill, C. (2017). A framework to explore roles within student-staff partnerships in higher education: Which students are partners, when, and in what ways? International Journal for Students as Partners, 1(1). https://doi.org/10.15173/ijsap.v1i1.3062

Bovill, C., Cook-Sather, A. \& Felten, P. (2011). Students as co-creators of teaching approaches, course design, and curricula: Implications for academic developers. International Journal for Academic Development, 16, 133145.

Bovill, C., Cook-Sather, A., Felten, P., Millard, L. \& Moore-Cherry, N. (2016). Addressing potential challenges in co-creating learning and teaching: Overcoming resistance, navigating institutional norms and ensuring inclusivity in student-staff partnerships. Higher Education, 71, 195-208.

Boyle, A., Maguire, S., Martin, A., Milsom, C., Nash, R., Rawlinson, S., Turner, A., Wurthmann, S. \& Conchie, S. (2007). Fieldwork is good: the student perception and the affective domain. Journal of Geography in Higher Education, 31, 299-317.

Carless, D., Salter, D., Yang, M. \& Lam, J. (2011). Developing sustainable feedback practices. Studies in Higher Education, 36, 395-407.

Carter, M.A., Pagliano, P., Francis, A. \& Thorne, M. (2017). Australian university students and mental health: viewpoints from the literature. International Journal of Innovation, Creativity and Change, 3, 1-25.

Cook, J.L. \& Cook, G. (2014). Child Development: Principles and Perspectives (2 ${ }^{\text {nd }}$ ed.). London, UK: Pearson. 
Cook, V. (2008). The field as a 'pedagogical resource'? A critical analysis of students' affective engagement with the field environment. Environmental Education Research, 14, 507-517.

Cook-Sather, A., Bovill, C. \& Felten, P. (2014). Engaging students as partners in learning and teaching: A Guide for faculty. San Francisco, CA: Jossey-Bass.

Curran, R. \& Millard, L. (2016). A partnership approach to developing student capacity to engage and staff capacity to be engaging: opportunities for academic developers. International Journal for Academic Development, 21, 67-78.

Deonna, J. A. \& Teroni, F. (2013). What role for emotions in wellbeing? Philosophical Topics, 41(1).

Department of Education and Early Childhood Development (DEECD) (2010). The Effectiveness of Student Wellbeing Programs and Services. Retrieved https://www.parliament.vic.gov.au/papers/govpub/VPARL2006-10No270.pdf [accessed 28 September 2018].

Efklides, A. \& Volet, S. (Eds.) (2005). Feelings and emotions in the learning process [Special issue]. Learning and Instruction, 15, 377-515.

Felten, P. (2017). Emotion and partnerships. International Journal for Students as Partners, 1, 1-5.

Felten, P., Gilchrist, L. \& Darby, A. (2006). Emotion and learning. Michigan Journal of Community Service Learning, 12, 38-46.

Felten, P., Bagg, J., Bumbry, M., Hill, J., Hornsby, K., Pratt, M. \& Weller, S. (2013). A call for expanding inclusive student engagement in SOTL. Teaching and Learning Inquiry, 1, 63-74.

Ferguson, D. (2017). The rise in student mental health problems - 'I thought my tutor would say: deal with it'. The Guardian, $29^{\text {th }}$ August 2017.

Forsythe, A. \& Johnson, S. (2017). Thanks, but no-thanks for the feedback. Assessment \& Evaluation in Higher Education, 42, 850-859.

Fredrickson, B. L. \& Joiner, T. (2002). Positive emotions trigger upward spirals toward emotional wellbeing. Psychological Science, 13, 172-175. 
Fuller, I., Edmondson, S., France, D., Higgitt, D., \& Ratinen, I. (2006). International perspectives on the effectiveness of geography fieldwork for learning. Journal of Geography in Higher Education, 30, 89-101.

Golubchikov, O. (2015) Negotiating critical geographies through a "feel-trip": experiential, affective and critical learning in engaged fieldwork. Journal of Geography in Higher Education, 39, 143-157.

Graetz, K. A. (2006). The psychology of learning environments. EDUCAUSE, 41, 6, 60-75.

Gutman, L. M., \& Vorhaus, J. (2012). The Impact of Pupil Behaviour and Wellbeing on Educational Outcomes. Research Report of the Institute of Education, University of London, Childhood Wellbeing Research Centre.

Healey, M., Flint, A. \& Harrington, K. (2014). Engagement through Partnership: Students as Partners in Learning and Teaching in Higher Education. York, UK: Higher Education Academy.

Healey, R., Healey, M. \& Cliffe, A. (2018). Engaging in radical work: Students as partners in academic publishing, Efficiency Exchange. Retrieved from: http://www.efficiencyexchange.ac.uk/12775/engaging-radical-workstudents-partners-academic-publishing/ [accessed 28 September 2018].

Hermsen, T., Kuiper, T., Roelofs, F. \& van Wijchen, J. (2017). Without emotions, never a partnership! International Journal for Students as Partners, 1(2).

Hill, J. \& West, H. (2019). Improving the student learning experience through dialogic feed-forward assessment. Assessment and Evaluation in Higher Education, (in print).

Hill, J., Thomas, G., Diaz, A. \& Simm, D. (2016). Borderland spaces for learning partnership: opportunities, benefits and challenges. Journal of Geography in Higher Education, 40, 375-393.

Hill, J., Walkington, H. \& King, H. (2018). Geographers and the scholarship of teaching and learning. Journal of Geography in Higher Education, 42, 557-572.

Hill, J., Walkington, H. \& Kneale, P. (2019). Borderland spaces: moving towards self-authorship. In T. Bilham, C. Hamshire, M. Hartog \& M. Doolan (Eds.) Reframing Space for Learning: Excellence and Innovation in University Teaching. London: UCL/IoE Press (in print). 
Jacklin, A. \& Robinson, C. (2007). What is meant by 'support' in higher education? Towards a model of academic welfare. Journal of Research in Special Educational Needs, 7, 114-123.

Johansson, C. \& Felten, P. (2014). Transforming students: Fulfilling the promise of higher education.

Baltimore, MD: Johns Hopkins Press.

Keltner, D., \& Haidt, J. (1999). Social functions of emotions at four levels of analysis. Cognition and Emotion, $13,505-521$.

Keltner, D. \& Lerner, J. (2010). Emotion. In S. Fiske, D. Gilbert, \& G. Lindzey (Eds.) Handbook of Social Psychology. Fifth Edition. San Francisco, CA: Wiley. pp. 317-352.

Kneale, P.E. (2018). Where might pedagogic research focus to support students' education in a REF-TEF world. Journal of Geography in Higher Education, 42, 487-497.

Krathwohl, D. R., Bloom, B. S. \& Bertram, B. M. (1964). Taxonomy of Educational Objectives. The Classification of Educational Goals, Handbook II: Affective Domain. New York, NY: David McKay.

Lerner, J., Li, Y., Valdesolo, P. \& Kassam, K. (2015). Emotion and decision making. Annual Review of Psychology, $66,799-823$.

Marvell, A. (2008). Student-led presentations in situ: The challenges to presenting on the edge of a volcano. Journal of Geography in Higher Education, 32, 321-335.

Marvell, A. \& Simm, D. (2018). Emotional geographies experienced during international fieldwork: an evaluation of teaching and learning strategies for reflective assessment. Journal of Geography in Higher Education, 42, 515-530.

Marvell, A., Simm, D., Schaaff, R. \& Harper, R. (2013). Students as scholars: evaluating student-led learning and teaching during fieldwork. Journal of Geography in Higher Education, 37, 547-566.

Matthews, K. E. (2017). Five propositions for genuine 'students as partners' practice. International Journal of Students as Partners, 1(2). https://mulpress.mcmaster.ca/ijsap/issue/view/318

Mercer-Mapstone, L., Dvorakova, S. L., Matthews, K. E., Abbot, S., Cheng, B., Felten, P., Knorr, K., Marquis, E., 
Shammas, R. \& Swain, K. (2017). A systematic literature review of students as partners in higher education, International Journal for Students as Partners, 1(1).

Moore-Cherry, N., Healey, R., Nicholson, D. T. \& Andrews, W. (2016). Inclusive partnership: Enhancing student engagement in geography. Journal of Geography in Higher Education, 40, 84-103.

Murphy, R., Nixon, S., Brooman, S. \& Fearon, D. (2017). 'I am wary of giving too much power to students': Addressing the 'but' in the principle of staff-student partnership. International Journal of Students as Partners, $1(1)$.

Orsmond, P., Maw, S. J., Park, J. R., Gomez, S. \& Crook, A. C. (2013). Moving feedback forward: theory to practice. Assessment and Evaluation in Higher Education, 38, 240-252.

Pang, W. (2017). Peace of mind: universities see spike in students seeking mental-health help. The Globe and Mail, $18^{\text {th }}$ October 2017.

Pekrun, R. \& Linnenbrink-Garcia, L. (Eds.) (2014). International Handbook of Emotions in Education. New York, NY: Routledge.

Ritchie, L. (2016). Fostering Self-Efficacy in Higher Education Students. London, UK: Palgrave.

Rose, G. (1997). Situating knowledges: positionality, reflexivities and other tactics. Progress in Human Geography, 21, 305-320.

Schutz, P. A. \& Pekrun, R. (2007). Emotion in Education. Amsterdam, NL: Academic Press.

Schwanen, T. \& Atkinson, S. (2015). Geographies of wellbeing: an introduction. Geographical Journal, 181, 98101.

Shulman, L. S. (2004). The wisdom of practice: Essays on learning, teaching, and learning to teach. San Francisco, CA: Jossey-Bass.

Shulman, L. (2005). Signature pedagogies in the professions. Daedalus, 134, 52-59.

Simm, D. \& Marvell, A. (2015). Gaining a "sense of place": students' affective experiences of place leading to transformative learning on international fieldwork. Journal of Geography in Higher Education, 39, 595-616. 
Winstone, N. E., Nash, R. A., Rowntree, J. \& Parker, M. (2017). 'It'd be useful, but I wouldn't use it': barriers to university students' feedback seeking and recipience. Studies in Higher Education, 42, 2026-2041.

Wright, S. \& Hodge, P. (2012). To be transformed: Emotions in cross-cultural, field-based learning in Northern Australia. Journal of Geography in Higher Education, 36, 355-368.

Zimmerman, B. J. (2000). Self-efficacy: an essential motive to learn. Contemporary Educational Psychology, 25, 82-91.

Zimmerman, B. J. (2002). Becoming a self-regulated learner: An overview. Theory into Practice, 41, 64-70.

Zimmerman, B. J. \& Martinez-Pons, M. (1990). Student differences in self-regulated learning: Relating grade, sex and giftedness to self-efficacy and strategy use. Journal of Educational Psychology, 82, 51-59. 